\title{
The Istituto Nazionale di Geofisica and its historical archives
}

\author{
Giuseppina Calcara \\ Istituto Nazionale di Geofisica e Vulcanologia, Roma, Italy
}

\begin{abstract}
Herewith are presented the contents of the ING (Istituto Nazionale di Geofisica) historical archives, recently reorganized to preserve and make available to scholars documents concerning the scientific activity and management of the Institute. The documents date from 1945, when the Institute became an independent board after separating it from the CNR (Consiglio Nazionale delle Ricerche) to 1965. It is a decisive period for the ING, which had been founded in 1936 by Guglielmo Marconi, president of the CNR at the time and by the physicist Antonino Lo Surdo, who became its first director until his death in 1949. These valuable papers document how the ING rose from the war destruction, expanded its seismic monitoring network and developed experimental and theoretical research in all the main fields of the Earth physics.
\end{abstract}

Key words historical archives - Istituto Nazionale di Geofisica - geophysical research - Guglielmo Marconi - Antonino Lo Surdo

\section{Introduction}

The reordering of the historical archives of the Istituto Nazionale di Geofisica (ING, National Institute of Geophysics), promoted by the Istituto Nazionale di Geofisica e Vulcanologia (INGV, National Institute of Geophysics and Volcanology) and recently completed in accordance with legislation enacted regarding the archives of public bodies - Legislative Decree October 29, 1999 n. 490 - was carried out to safeguard the acquired heritage of historical documents and, at the same time, render these documents more easily accessible.

Mailing address: Dr. Giuseppina Calcara, Istituto Nazionale di Geofisica e Vulcanologia (INGV), Via di Vigna Murata 605, 00143 Roma, Italy; Temporarily attached to Archivio Centrale dello Stato, Piazzale degli Archivi 27, 00144 Roma, Italy; e-mail: giuseppina.calcara@ingv.it; giuseppina.calcara@beniculturali.it
These archives include all the documents produced by the Institute during its operating years from 1945 to 1965 .

\section{The Foundation}

The ING was actually founded in 1936 as an institute of the Consiglio Nazionale delle Ricerche (CNR, National Research Council) and the documents produced from this date until 1944 are therefore considered to belong to the CNR and are stored in the Archivio Centrale dello Stato (ACS, Central Archives of the State). The idea to create a geophysics institute came about during the 1930's and can be attributed to the CNR's top management. Until this time, the Ufficio Centrale di Meteorologia e Geofisica (Central Office of Meteorology and Geophysics, so called since 1923) was responsible for geophysics activity. Several observatories and stations, public as well as private, were distributed throughout the territory (Kingdom of Italy). However, they worked and carried out their geophysical prospecting research and observation campaigns independently of one another. 
The discoveries made in fundamental physics in the early decades of the 1930's led to an increase in more in-depth research in several branches of geophysics-physics of the atmosphere, cosmic ray, and terrestrial magnetism. These areas had, until then, each been researched separately and still laboured under the yoke of their original naturalistic imprint (Dominici, 1986).

The study of geophysics, according to Antonino Lo Surdo, professor in charge of earth physics studies at the University of Rome at the time, could not be separated from a «coordinated functioning of a homogeneous group of laboratories and observatories» (ING, 1945) or from the systematic gathering of data carried out by qualified personnel in dedicated institutes. In fact, Lo Surdo firmly believed in the practical applications of research results in fields such as communications, defence, public works, and mining activities. It is therefore evident that the reasons behind the need to reorganize geophysical research and services under a single, centralized, national leadership were manifold.

An initial draft for the soon-to-be-founded geophysics institute was presented by Gino Cassinis (full professor of Topography and Geodesy at the Milan Polytechnic, and also secretary of CNR Commettee of Geodesy and Geophysics) on May 8, 1936 during a meeting of the CNR Executive Board, which in those days was composed of Guglielmo Marconi (President), Ugo Frascherelli (General Secretary) and Vincenzo Azzolini (Managing Director). Some time later, Antonino Lo Surdo announced his own project draft in which he outlined an institute divided into five divisions, each specialized in a different area of geophysics: seismology, terrestrial and atmospheric electricity, atmospheric optics and radiation, meteorology and terrestrial magnetism. These divisions were to include a network of stations, laboratories and workshops (CNR, 1936a).

After having examined both these project drafts, the Executive Board decided that the two were not that dissimilar and charged its secretary general, Ugo Frascherelli, with the task of integrating them (CNR, 1936b).

So, in November 1936, the papers creating the National Institute of Geophysics were officially signed into an act and Antonino Lo Surdo was appointed director (fig. 1). The funds necessary for setting up an initial installation were authorized and headquarters were established within the offices of the Higher Institute of Physics at the «La Sapienza» University of Rome.

\section{The National Geophysical Network}

Among the various research activities performed by the Institute, seismology studies represented the principal line of inquiry to which all the geophysicists of the staff (Pietro Caloi, Guido Pannocchia, Francesco Peronaci, Ezio Rosini) dedicated their efforts, carrying out studies on the composition of the Earth, the characteristics of superficial and inner stratifications, the propagation of seismic waves, and on methods for determining the absolute intensity of macro-seismic events (Lo Surdo, 1940). September 1, 1938 marked the beginning of recording activity at the «experimental seismic station «, albeit using a limited number of instruments installed in dedicated areas of the headquarters. This was to become the foundation of the budding national seismic network.

As far as other research fields were concerned - ionosphere, cosmic rays, atmospheric electricity - the Institute also availed itself of the collaboration of other University physicists who, under contract, carried out research work for the Institute in their field of specialization. For example, studies regarding the ionosphere were entrusted to Ivo Ranzi who, in 1938, came up with the first instrument for atmospheric radio sounding; one of the few of its kind in the world at that time. The cosmic ray research group was made up of Gilberto Bernardini, Bernardo N. Cacciapuoti, Marcello Conversi, Mario Ageno and Oreste Piccioni. Lo Surdo, together with Guglielmo Zanotelli, conducted scientific inquiries into microwave physics, while Enrico Medi was involved in atmospheric electricity studies. Among the papers deposited in the archives, there is also a testimony regarding applied research carried out for the military, performed by Lo Surdo himself and commissioned by the War, Navy and Air Ministries. 


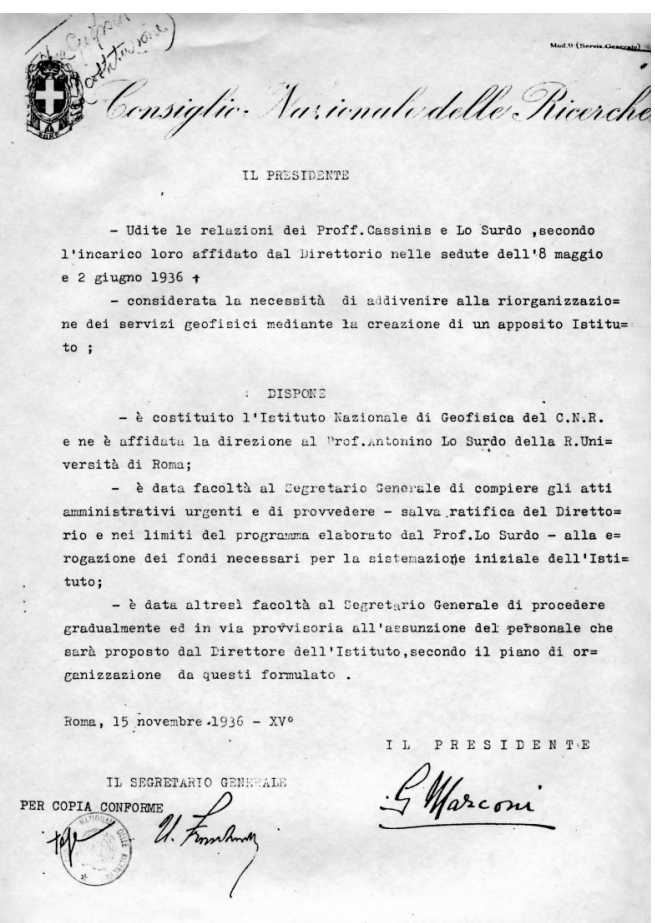

Fig. 1. Resolution establishing the Istituto Nazionale di Geofisica (Nov. 15, 1936).

One of the most important tasks of the institute was that assigned by Parliamentary Act January 5, 1939 no. 18, whereby the responsibility for geophysics services was transferred from the Ufficio Centrale di Meteorologia to the CNR and therefore on to the ING. This reorganization of services involved the creation of a nationwide geophysics network made up of a seismic network and several stations for the study of the ionosphere, atmospheric electricity and geomagnetism.

The draft presented by Lo Surdo for the organization of the network and discussed in May 1940 read that «with the exception of explicit changes made», this network was to be made up of «main stations»: in Rome, Pavia, Rocca di Papa, and Messina; and of «minor stations»: in Salò, Padua, Udine, Genoa, Bologna, Florence, Pisa, Bari, Foggia, Cuglieri, and in Calabria.

«Special stations» were also provided for: in
Naples, including the clinometric station on Vesuvius; in Catania, including the clinometric station on Mount Etna; a station for atmospheric electricity in Rome at St. Alessio; and in Trieste (CNR, 1940). The distinction between observatory and station was for all practical purposes established. The observatories were to be for the purpose of detecting as many observable natural phenomena as possible via the installation of various types of apparatus, and for carrying out experimental studies and research which would mark them as study centres; each would have a resident geophysicist as station director along with a support staff of technicians and assistants (ING, 1954). The stations were to be of a smaller size, with the installation of specialized instruments regarding, among others, seismic, meteorological, and electricity studies. The stations, for the most part, were run by a director, often a professor and in any case an expert in the field at hand, along with a technician.

Several of the buildings in which the observatories and stations were located were the property of the Institute others were set up under contract in schools, universities and religious institutes (see the inventory, series «X - Istituti, osservatori e stazioni», for more informations).

Notwithstanding the difficulties created by the ongoing war, in 1942 saw the seismic observatories in Catania, Genoa, and Padua, along with the seismic stations in Rome, Bologna and Salo' became operative. Twelve kilometres from Rome, on the Via Ardeatina at St. Alessio, an observatory for studies on atmospheric electricity phenomena and terrestrial and solar radiation was running (CNR, $1943 \mathrm{ca}$.).

Correspondence between the heads of the observatories and stations in Rome provide an insight into how the setting up and running of the network continued non-stop until the spring of 1943: slowing down after the summer of that year as the conflict became more intense following the landing of the Allied troops.

\section{The ING Autonomy}

The ING officially became an autonomous, non-profit organization under the supervision of the Ministry of Education by delegated de- 


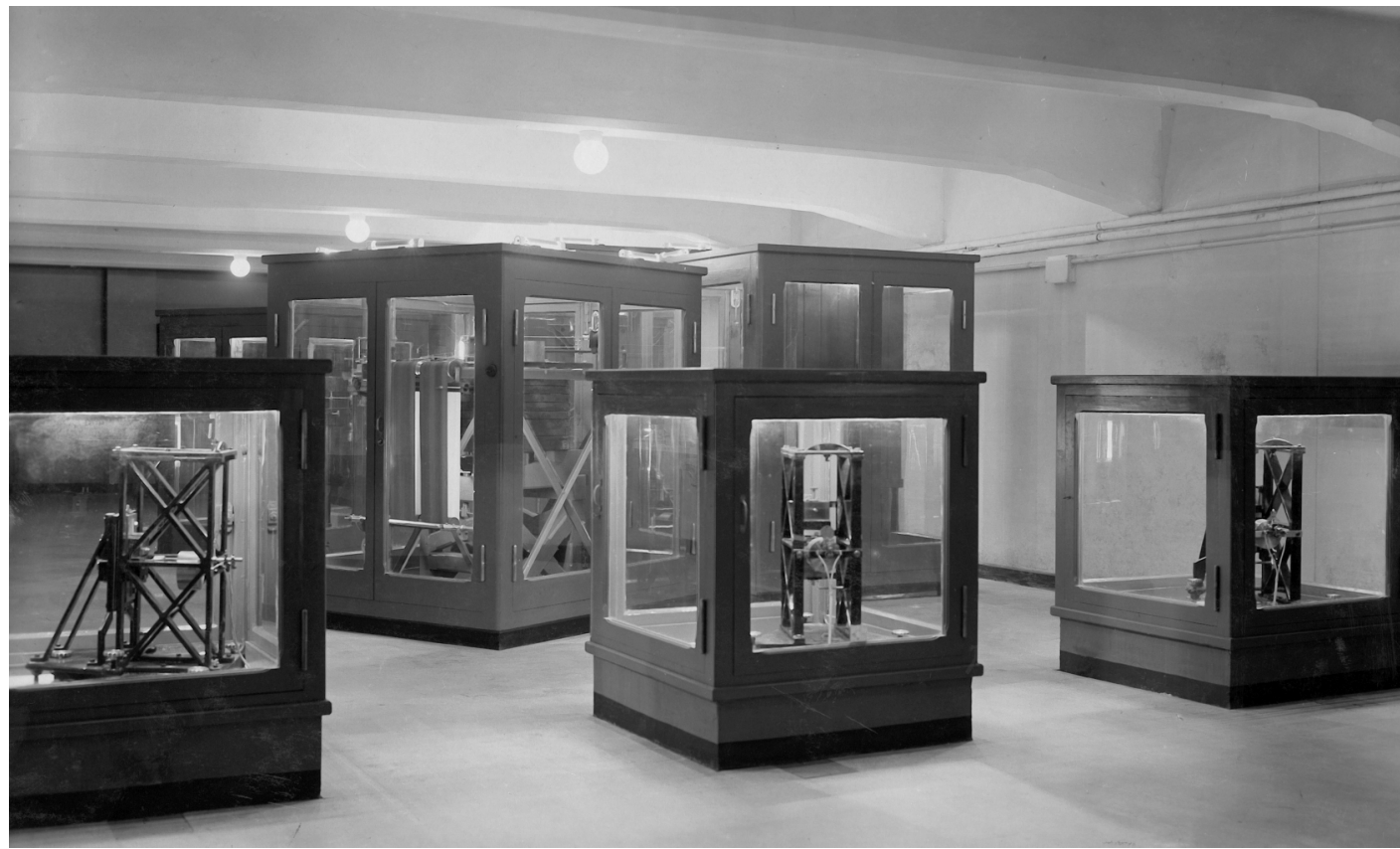

Fig. 2. Galitzin seismographs installed at Roma seismic station (1939).

cree «luogotenenziale» March 3, 1945 no. 82. When the decree became effective, the ING's statute was drawn up defining its institutional obligations (Decree of temporary head of State December 13, 1946 n. 731), its administrative and management organigram, along with their responsibilities, norms and regulations regarding the staff, which was to include forty persons. The Institute was organized with a Director (Chairman of the Board), a Board of Directors, an Administrative Board, an Advisory Committee, and an Audit Board.

Once a legal entity in its own right, the Institute had to face the issue of financing. In 1945 the Ministry of the Treasury assigned interim financing of 2,030,000 liras; $80 \%$ of the funds went to cover expenses for personnel. Lo Surdo requested a substantial increase in these funds in order to be able to finance the scientific activity and the functioning of the Institute itself.

Parliamentary Act October 16, 1947 no. 1293 allotted an annual sum of 26,000,000 liras, along with a lump sum of 13,460,000 liras to allow the Institute to face its most pressing problem of starting up activities again after the war. Among these were: rebuilding and repairs to structures damaged during the conflict (Rocca di Papa, St. Alessio, Genoa, Salò, Bologna, Florence, Naples); completion of the new equipment for the seismic network that would include stations in Bari, Palermo and Cagliari; the construction of new ionosphere apparatus and four stations for atmospheric electricity studies; continued research into the best sites for the magnetism observatory and its network.

A paper filed in June 1948 reports on the situation: the seismic network had at that time fourteen stations and observatories - University of Rome, Trieste, Padua, Salò, Pavia, Genoa, Bologna, Florence, Rocca di Papa, Naples (two stations), Catania and Messina -, along with a seismic station in Merano. The atmospheric electricity division had its main observatory in Rome at St. Alessio, the radiations and atmospheric optics division had its offices, equipment and instruments in the observatory at Rocca di 
Papa. The Institute was charged with the task of setting up a nationwide network for magnetism studies made up of a central, main observatory and several peripheral stations (ING, 1948a).

As for the Institute's scientific production, twelve years of scientific research saw 150 monographs and published papers «regarding original work in geophysics carried out within the Institute»(ING, 1948b). Moreover, the ING's Director had founded a journal entitled Annali di Geofisica (first published in 1948) to which many illustrious foreign seismologists contributed: among these J.P. Rothe', K.E. Bullen, L. Mintrop, B. Gutenberg, V. KeylisBorok, E. Teysseyre.

\section{Post-war Organization}

When Lo Surdo died (Rome, June 7, 1949), Enrico Medi became the Institute's Director, inheriting a well consolidated and organized research body and an already operating geophysics network. Undoubtedly, there was still much to be done: complete the seismic network, set up new stations for atmospheric electricity studies, institute a nationwide magnetism observatory.

An increase in funding, amounting to 76,000,000 liras annually (Parliamentary Act December 28, 1950 no. 1138), made it possible for the new Director to complete the tasks undertaken and increase financing to the laboratories, stations and observatories. Cost for personnel accounted for one third of the government's allotment and it was therefore possible to hire new staff via state examinations.

Throughout the early 1950's, seismology continued to be the Institute's most important branch of activity, enjoying international recognition for the studies carried out by Pietro Caloi (Caloi, 1954).

A special issue of the Annali di Geofisica, printed in 1954 for the X IUGG (International Union of Geodesy and Geophysics) Congress held in Rome, contains a list of observatories and stations which made up the national geophysics network at that time (observatories: Oropa, Genoa, Pavia, Salo', Merano, Pieve di Cadore, Trieste, Monte Cimone, Corinaldo,
Rocca di Papa, Rome St. Alessio, Rome University, L'Aquila, Reggio Calabria, Gibilmanna, Messina, Cuglieri, Vesuvius; stations: Asiago, Padua, Bologna, Florence, Catania, Palermo, Tormezzo, Siena). Every two weeks the seismic division published a provisional draft bulletin and every month, a final version containing the results of the elaborations of the network data.

The ionosphere division had two stations set up in St. Alessio. Data recorded there was elaborated and sent in monthly bulletins to international data collection centres. The importance of ionosphere data had grown considerably in those years and as a consequence the Institute had assumed the role of providing ionosphere sounding services for the entire national territory (experimental studies began in 1956).

Scientific inquiries regarding terrestrial magnetism surged forward in the 1950's; experimental studies began with the recording of magnetic events via instrumentation installed in the Marches (Corinaldo) and in Asiago and headquarters for the main magnetism observatory were established at the end of the decade in Masseria Calore, near L'Aquila.

Between the end of the 1950's and the beginning of the 1960 's, profound changes occurred in the field of «observational geophysics» (Dominici, 1986) influencing the very way this science was perceived and as a consequence deeply affecting the development of the Institute itself. Most importantly, the interdisciplinary nature of earth physics studies was recognized - up until that time, each area had worked and operated independently. Advances in the field of «solid state electronic devices» provided a new system, telemetry, which vastly improved observation quality, making it possible to select sites that were more remote and therefore less disturbed by anthropic noise and then connecting these sites to operators via telephone cables or radio link. These scientific innovations widened the horizons of geophysics research and the Institute found it absolutely necessary to overhaul its organizational structure and technical hardware. Papers and documents, minutes of meetings of the Board of Directors, illustrate this concern as well as the acknowledgement of the need in 1957 to operate 
a reform that will bring the Institute up to date in accordance with the demands imposed by «developments in the field of geophysics in recent years» (ING, 1957) - two years later, the Ministry of Education was officially involved in this process. In the meantime, the Director proposed to set up a Commission to study a revision of the statute (which changed several years later by Decree of the President of the Republic December 8, 1971 n. 1425, in vigour May 1972, with the first internal regulation approved by interdepartmental Decree March 21, 1973). This Commission, whose findings were published in 1961, suggested a considerable increase in personnel and financing. The emphasis placed on an increase in numbers rather than on an improvement in quality probably came about as a result of an underestimation of the substantial and important changes that a reorganization of technology would have brought about - had the funds available been invested in instrumentation for the head offices and in a renewal of network apparatus, there would have been a net decrease in the need for personnel.

From an analysis of the financial resources available to the Institute, it can be seen that the contribution it received in 1962 was exactly the same as that accorded the previous decade. However, the fixed and reflected charges had increased by $80 \%$, leaving a margin of only $20 \%$ for research costs (surveying, maintenance of the observatories, scientific equipment and instruments). In fact, the last investment increase for the network can be traced back to the early 1950's and the structural upkeep of the observatories was possible only because of contributions by local bodies or by special government funding (the same occurred for Gibilmanna, Castel Tesino and L'Aquila). Investments in research and scholarship programs were proposed by the Institute's Director at the beginning of his term of office, but they remained only proposals. No new hiring through state exams was undertaken, even though there were posts for geophysicists to be filled.

In an effort to find a solution to its financial problems, a series of appeals was addressed to the Ministry in 1961 requesting a revision of the annual allowance. In the meanwhile, in March of 1958 Medi, already a Member of Par- liament and university professor, was nominated vice-president of Euratom in Brussels and he, in turn, empowered Guglielmo Zanotelli, his close collaborator and board advisor, to sign administrative documents and payments. The management of the direction of the Institute began to be conducted via correspondence (ING, 1958) and, as a consequence, all the decisionmaking and its enactment became more and more protracted in time.

The board's appeals for increased funding fell for the most part on deaf ears, with the exception of a series of special budget appropriations: one for 20,500,00 liras Parliamentary Act March 5, 1961 no. 158 for the purchase of equipment and apparatus for the main offices and for L'Aquila and Gibilmanna; an additional 2,500,000 liras to supplement the annual budget; another for 12,500,000 liras in order to improve salary levels. The financing accorded by Parliamentary Act July 24, 1962 no. 1073, amounting to $75,000,000$ liras annually for a period of three years, saved the Institute in extremis from total paralysis.

\section{Archives contents}

The ING archives are stored in the central offices of the Istituto Nazionale di Geofisica e Vulcanologia in Rome. It is important to note that the documents and papers produced by the ING were discovered a few years ago in the offices of the Observatory at Rocca di Papa where they had been transferred prior to 1980 (see the inventory introduction for more detailed information and for the reordering criteria). They were in complete disarray, grouped in stacks without binders or envelopes of any kind, but nonetheless in fairly good condition. Various types of documents and papers were found: ranging from minutes of meetings, resolutions, agreements, contracts, personnel files and administrative-accounting records - ledgers and orders; to correspondence, station logs, scientific-technical reports, maps, photographic and printed material.

Files regarding ex-CNR personnel transferred to the ING were assigned to the safekeeping of the Institute in 1945 at the signing of 
those agreements which stipulated the presentday relationship between the newly founded body and the CNR.

Without any doubt, some records have gone astray and it has not been possible to trace when or how they were lost or misplaced.

This collection of documentation, records and papers offers ample opportunity for study for those interested in the history of the first Italian institute dedicated to geophysics, both from an institutional and administrative historical view point and for the retracing of the steps taken by Italian geophysics research between the first and second half of the twentieth century.

\section{REFERENCES}

Archive sources

CNR (1936a): Istituto Nazionale di Geofisica, project by A. Lo Surdo, Rome, Archivio Centrale dello Stato (ACS), CNR, Istituto Nazionale di Geofisica, box. 1, file 2.

CNR (1936b): Summary of the minutes of the Executive Board meeting, held July 1, 1936, ACS, CNR, Istituto Nazionale di Geofisica, box 2, file 2.

CNR (1940): Minutes of the Executive Board meeting held May 27, 1940, ACS, CNR, Istituto Nazionale di Geofisica, box 1 , file 1 .
CNR (1943 ca.): ING Activity during 1941-1942, report by A. Lo Surdo, 1943 ca., ACS, CNR, series Istituti e Centri di ricerca pos. 10 pg, box 2006 (temp. reference number), file «10 pg. Attività. Istituto Nazionale di Geofisica» (in arrangement).

ING (1945): ING Activity, report by A. Lo Surdo, 1945, Rome, Istituto Nazionale di Geofisica e Vulcanologia (INGV), $I N G$, box 12 , file 4 .

ING (1948a): Minutes of the Board of Directors meeting held October 28, 1948, INGV, ING, box 5, file 1 .

ING (1948b): Minutes of the Board of Directors meeting held June 24, 1948, INGV, ING, box 5, file 1 .

ING (1957): Minutes of the Board of Directors meeting held November 11,1957, INGV, ING, box 5, file 1 .

ING (1958): Delega.Corrispondenza col Sig. Direttore. 1958. Zanotelli, INGV, ING, box 11, file 6 .

\section{Bibliography}

CALOI, P. (1954): L'Astenosfera come canale-guida dell'energia sismica, in Annali di Geofisica, 7, 491-501.

Dominici, P., L'Istituto Nazionale di Geofisica dalla sua costituzione all'attuale assetto statutario 1936-1983, speech given at the fiftieth anniversary celebration of the Institute, Roma, December 12, 1986; courtesy of Dr. Guido Dominici (INGV).

Istituto NAZIONALE di GeOFISICA (INGV) (1954): supplement to Annali di Geofisica, 1954, pp. 5-86.

Lo SuRdo, A. (1940): La registrazione e lo studio dei fenomeni sismici nell'Istituto Nazionale di Geofisica del CNR, La Ricerca Scientifica , XI (10), 1-23. 